\title{
LA ENSEÑANZA DE LA REDACCIÓN PERIODÍSTICA EN EL NUEVO ESCENARIO DEL ESPACIO EUROPEO DE EDUCACIÓN SUPERIOR (EEES). LA COORDINACIÓN DOCENTE DEL PROGRAMA DE PRÁCTICAS EN EL GRADO EN PERIODISMO
}

Hugo Doménech-Fabregat': Universitat Jaume I. España hdomenec@uji.es

Pablo López-Rabadán: Universitat Jaume I. España rabadan@uji.es

\section{RESUMEN}

Las asignaturas vinculadas a la redacción periodística representan un contenido central dentro del plan de estudios del Grado en Periodismo en la Universitat Jaume I (UJI) ya que están directamente relacionadas con la adquisición de importantes competencias profesionales. En este sentido, es posible definir un módulo docente formado por cuatro asignaturas distribuidas en el segundo y tercer curso del grado (Géneros Periodísticos I, Géneros Periodísticos II, Géneros Periodísticos de análisis y opinión, y Periodismo especializado). Más allá de su fundamentación teórica, todas las asignaturas de este módulo se caracterizan por un abordaje práctico que busca capacitar a los alumnos en la elaboración profesional de contenidos periodísticos. En consecuencia, el peso de la parte práctica representa en todas ellas entre el $60 \%$ y $75 \%$ del total de la evaluación. Además, la ubicación sucesiva de estas asignaturas, y el fuerte carácter progresivo de sus contenidos y competencias profesionales asociadas, demanda una notable coordinación pedagógica para su correcto desarrollo. A partir de la experiencia de los primeros años de implantación del Grado, esta comunicación ofrece una propuesta metodológica para la coordinación del módulo a partir de tres resultados principales: un programa de prácticas organizado por fichas individuales; un modelo de evaluación conjunto para las cuatro asignaturas; y un cronograma global que articula su correcto desarrollo a lo largo de los cursos centrales del grado.

\footnotetext{
${ }^{1}$ Autor correspondiente

Hugo Doménech-Fabregat: Profesor colaborador. Universitat Jaume I. Castellón España.
} 
PALABRAS CLAVE: Grado Periodismo - Redacción periodística - Coordinación asignaturas - Programa prácticas - Criterio Evaluación

\title{
THE TEACHING OF JOURNALISTIC WRITING IN THE NEW STAGE OF EUROPEAN HIGHER EDUCATION AREA (EHEA). COORDINATION OF PRACTICE PROGRAMME IN THE GRADE IN JOURNALISM
}

\begin{abstract}
The subjects related to journalistic writing represent a central content of the curriculum in the Degree in Journalism at the Universitat Jaume I (UJI) as they are directly related to the acquisition of important professional skills. In this sense, it is possible to define a teaching module consists of four subjects distributed in the second and third year of degree (Genres Journalistic Genres I, Journalistic Genres II, Journalistic Genres of analysis and opinion Journalism, and Specilized Journalism). Beyond its theoretical foundation, all subjects from this module are characterized by their practical approach that seeks to train students in developing professional journalistic content. Consequently, the weight of the practice is in all of them between $60 \%$ and $75 \%$ of the total evaluation. Furthermore, the successive location of these subjects, and the strong progressive nature of its contents and associated professional competencies demands a remarkable pedagogical coordination for its proper development. From the experience of the first years of degree implementation, this paper provides a methodological proposal for the coordination of the module from three main results: a practice program organized by individual files; a joint evaluation model for the four subjects; and a global schedule that articulates its development along the core courses of the degree.
\end{abstract}

KEY WORDS: Journalism grade - Journalistic writing - Subject coordination Practice programme -Evaluation criteria

\section{INTRODUCCIÓN}

1.1 Renovación de los estudios de periodismo ante el reto del Espacio Europeo de Educación Superior (EEES). 
técnicas solidarios con las necesidades nuevas y de todos" (Cruz Tomé, 1999). Como recoge la Carta Magna de las Universidades Europeas, "la Universidad es una institución autónoma que produce y transmite cultura de una manera crítica". Así, la Universidad debe responder a estos ambiciosos retos a través de la función creadora, la preparación para el mundo profesional futuro, el fomento del desarrollo de la sociedad y la transmisión de la cultura universitaria.

La preparación para el mundo profesional se conseguirá, por tanto, "salvando los desajustes actuales entre formación universitaria y capacitación profesional que la nueva sociedad y el mercado de trabajo exigen, y la formación permanente a lo largo de la vida" (Michavila \& Calvo, 1988). De este modo, la institución universitaria cumple un papel de liderazgo fundamental en las actuales sociedades avanzadas. Su función prioritaria consistirá en crear los conocimientos, propagarlos, desarrollar y disciplinar a la inteligencia, formar a los estudiantes por su cultura y su capacidad.

Ante este nuevo contexto, la actualización de los planes de estudio, se plantea como un reto no exento de dificultades: nuevos y cada vez más heterogéneos estudiantes, la mundialización en el intercambio de conocimientos, las nuevas tecnologías de la información, las exigencias de calidad, la permanente renovación y actualización de contenidos, los sistemas de formación a distancia, etc. Sin duda, la respuesta a estos retos pasa por el planteamiento de una formación especializada desde las respectivas áreas de conociento basada en la investigación sobre el contenido de su materia y las formas de transmitir dichos contenidos.

\subsection{La Universidad como nexo entre la ciencia y la sociedad}

Uno de los principales problemas a los que ha de hacer frente la educación universitaria es su relación con el resto de la sociedad. Por un lado, ante los nuevos aportes de la ciencia y la tecnología, se alzan voces pidiendo una mejor formación de un alumnado poco preparado y aislado de la realidad social y laboral cambiante; y por otro lado, se hace necesaria una revisión de las actuales relaciones entre la sociedad y la Universidad dentro de un nuevo marco educativo común europeo.

En esta relación, el profesorado, en tanto que miembro a la vez de la sociedad y de la Universidad, se presenta como vínculo indispensable entre dos esferas demasiado alejadas hasta ahora una de la otra, herederas de un sistema educativo obsoleto en nuestros días. Es el profesorado, gracias a una formación permanente a lo largo de su carrera profesional y a la adquisición de una serie de capacidades, sobre quien recae tal reto. Desde esta perspectiva, creemos que la vieja definición de Universidad como lugar de adauisición del saber debe evolucionar hacia una nueva definición de la 
Esta es, no en vano, la finalidad del actual Espacio Europeo de Educación Superior (EEES), entre cuyos objetivos, junto a la armonización de los contenidos curriculares, se fijan medidas como la unificación de diplomas y contenidos, la evaluación de los niveles de calidad o la promoción de la movilidad de estudiantes, profesores y personal administrativo, encaminadas todas ellas a hacer de la Universidad un espacio más presente en la sociedad. Medidas, a su vez, que involucran por igual a todos los actores universitarios: alumnado, administración y profesorado.

Este cambio estructural de la Universidad española debería ir acompañado necesariamente de cambios que contribuyan a la modernización de la metodología de enseñanza-aprendizaje y en la evaluación, que fomenten la formación de los estudiantes no sólo en conocimientos, sino también en competencias.

Los pilares de esta reforma acometida son la autonomía universitaria combinada con una rigurosa rendición de cuentas. En la organización de las enseñanzas, la autonomía se plasma en la capacidad de las universidades para diseñar el currículo de los títulos. La rendición de cuentas se basa en un proceso de verificación a priori y un seguimiento posterior del desarrollo y evaluación de resultados a posteriori. Todo ello basado en referentes externos, nacionales e internacionales, que nos permitan disponer de un sistema de acreditación de títulos reconocible por otros países.

El proceso de construcción del EEES no debería quedarse en una mera reconversión de la estructura y contenido de los estudios, sino que debe implicar la interacción de profesores y estudiantes para la generación de aprendizaje. Así pues, habrá que complementar los métodos docentes tradicionales con las técnicas docentes basadas en aprendizaje activo para fomentar la participación del estudiante, otorgándole un mayor protagonismo.

Además, el impulso de acciones encaminadas a crear un proceso participativo entre la comunidad docente, el intercambio de experiencias y coordinación docente deben proporcionar una respuesta a las necesidades educativas surgidas de estos cambios sociales. Además, las administraciones a través de una correcta renovación de sus programas educativos deben contribuir a dar una mejor respuesta a los problemas actuales y concretos del profesorado, permitiéndole mejorar su práctica docente, lo que sin ninguna duda repercutirá en el aprendizaje del alumnado y en la calidad educativa, dando lugar, en consecuencia, a una Universidad más moderna y cercana de la sociedad actual y futura. 


\subsection{El Grado en Periodismo en la Universitat Jaume I}

El título de grado en Periodismo se centra en el estudio de la información periodística y sus diferentes géneros, formatos y productos. En este sentido, el Grado en Periodismo de la Universitat Jaume I (UJI) ofrece una formación innovadora y orientada al ejercicio profesional. Para conseguirlo propone al alumnado una plan de estudios que combina una visión global sobre el campo de la comunicación con el estudio profundo de los géneros periodísticos (Martínez Albertos, 2004; Gomis, 2008; Armentia, 2009), entre otras materias. Así, gracias al privilegio concedido a la praxis, se pretende una aproximación garantizada a los tres objetivos básicos que vertebran el presente plan de estudios:

a) Capacitación técnica y profesional para el ejercicio del periodismo,

b) Formación global en el campo de las Ciencias de la Comunicación,

c) Potenciación de las habilidades relacionadas con la innovación y la creatividad en la realización de contenidos periodísticos a partir de una equilibrada combinación entre la concepción y la ejecución técnica a la hora de elaborar los productos periodísticos.

Los graduados/as en Periodismo por la UJI adquirirán competencias que les permitirán elaborar todo tipo de productos periodísticos para cualquier medio de comunicación, desarrollar funciones de dirección de gabinetes de prensa de empresas o instituciones públicas y, en general, gestionar y editar contenidos periodísticos en el entorno de Internet.

Concretamente, el título de graduado/a en Periodismo de la Universitat Jaume I (UJI) cuenta con un total de 240 ECTS y se estructura en cuatro cursos académicos. Cada curso se organiza en dos periodos académicos de 20 semanas cada uno, denominados semestres. El semestre incluye el periodo lectivo y el periodo de exámenes. La Universitat Jaume I ha fijado un número de 25 horas de dedicación por ECTS para el estudiantado. De tal dedicación, la presencialidad es de entre el 30\% y el $40 \%$. Todas las asignaturas que componen el plan de estudios, incluidas las vinculadas al módulo de Redacción Periodística, son de 6 créditos ECTS (a excepción de las prácticas externas y la mayoría de las optativas que son de 4,5).

\subsection{Nuevos principios de evaluación}

El cambio que supone la adaptación al Espacio Europeo de Educación Superior (EEES) incumbe muy de cerca a los actuales sistemas de evaluación implementados en la Universidad española. El diseño de nuevas metodologías de evaluación para el 
El profesor universitario ante el EEES debe ser capaz de planificar las actividades de aprendizaje apropiadas a los objetivos y necesidades diversas de los estudiantes, desplazando el centro de referencia desde la enseñanza al aprendizaje (IbañezMartín, 1990).

Así pues, debe partirse de una evaluación inicial de necesidades (test de prerrequisitos); corresponde al profesor introducir y evaluar progresivamente las tecnologías de la información y de comunicación como recurso docente; se requiere programar las unidades didácticas mediante la identificación y selección de objetivos, contenidos, métodos, recursos y procedimientos de evaluación coherentes con los procesos de enseñanza-aprendizaje (evaluación continua y final).

En el siguiente cuadro explicativo se muestran los tres tipos de evaluación posible (diagnóstica, formativa y sumativa), y algunas de las características fundamentales de los mismos:

Tabla 1. Tipos de evaluación

\begin{tabular}{|c|c|c|c|}
\hline & DIAGNÓSTICA & FORMATIVA & SUMATIVA \\
\hline ¿Cuándo? & Inicio curso & Durante curso & Final curso \\
\hline ¿Cómo? & $\begin{array}{l}\text { Pruebas objetivas } \\
\text { estructuradas que } \\
\text { exploren o } \\
\text { reconozcan la } \\
\text { situación real de los } \\
\text { estudiantes en } \\
\text { relación } \\
\text { con el curso. }\end{array}$ & $\begin{array}{l}\text { Pruebas o trabajos } \\
\text { informales, } \\
\text { exámenes } \\
\text { prácticos, etc. }\end{array}$ & $\begin{array}{l}\text { Pruebas objetivas que } \\
\text { incluyan muestras } \\
\text { proporcionales de la } \\
\text { totalidad de los } \\
\text { objetivos } \\
\text { de la asignatura que } \\
\text { va a calificarse }\end{array}$ \\
\hline
\end{tabular}

Siguiendo las aportaciones de Stufflebeam y Tenbrick (Stufflebeam \& Tenbrick, 1987) y Tenbrick (Tenbrick, 1988), se define la evaluación del conocimiento y su adquisición como el proceso de obtención de información y de su uso para formular juicios que, a su vez, se utilizan para tomar decisiones. De este modo, la evaluación es un proceso, no una actividad aislada y con un fin en sí misma, que ha de ser diseñada en función de los objetivos y finalidades de la evaluación, y ha de traducirse en juicios de valor 
Como conclusión, se puede subrayar que la evaluación constituye, en sí mismo, uno de los modos más realistas y ajustados para desplegar una reflexión sobre todo el proceso de enseñanza-aprendizaje (Rosales, 1990). Es importante resaltar que la evaluación de la propia práctica docente, se muestra como una de las estrategias de formación más poderosas para mejorar la calidad del proceso de enseñanzaaprendizaje. En este sentido, y desde una perspectiva constructivista, la evaluación del conocimiento y su adquisición debe ser siempre continua, personalizada, formativa y sistémica.

\section{METODOLOGÍA}

La presente investigación emplea el método la generalización para expresar las regularidades esenciales que caracterizan las relaciones, características y regularidades de la carrera de Periodismo, para ofrecer una propuesta metodológica para la coordinación del módulo a partir de tres resultados principales: un programa de prácticas organizado por fichas individuales; un modelo de evaluación conjunto para las cuatro asignaturas; y un cronograma global que articula su correcto desarrollo a lo largo de los cursos centrales del grado.

\section{ANÁLISIS Y DISCUSIÓN}

\subsection{Características del módulo de Redacción periodística}

\section{Importancia dentro de la titulación}

La Redacción Periodística, según la define López de Zuazo (1977) en su Diccionario de Periodismo sería aquella ciencia que forma parte sobre los estudios sobre información y cuyo objetivo prioritario consiste en el análisis tanto de la forma como del contenido del mensaje. De forma más precisa, Martínez Albertos señala que "la disciplina Redacción Periodística no es un simple repertorio de técnicas para escribir en los periódicos" (Martínez Albertos, 2004).

En este mismo sentido podemos precisar que dichos estudios privilegian tanto "la selección y valoración de hechos informativos como la redacción y el análisis del mensaje periodístico" (Casasús, 1988, p. 2); es decir, y tal como significaremos a continuación, dispensan tanto valor a la teoría como a la parte práctica. Por tanto, y siguiendo estas apreciaciones, consideramos que el módulo de Redacción Periodística englobaría a aquellas asignaturas del Grado que "se refieran fundamentalmente a la compilación, ordenación y expresión del mensaje periodístico" (Armentia \& Caminos, 2003, p. 51). 
La asignatura Géneros Periodísticos (PE0914- Carácter obligatorio. 6 créditos ECTS) es una materia impartida durante el primer cuatrimestre del segundo curso del grado en Periodismo se centra en presentar los principales métodos de trabajo que se aplican en el campo del Periodismo para la elaboración de productos de naturaleza informativa. En este sentido, se estudia el proceso de tratamiento, gestión y edición de contenidos periodísticos de tipo informativo. Con ello, se pretende ofrecer conocimientos teórico-prácticos para que el alumnado sea capaz de crear mensajes periodísticos de tipo informativo (Armentia \& Caminos, 2009).

Para ello, se presta una especial atención a los productos periodísticos asociados a la información. Así, se estudia, desde un enfoque teórico-práctico, la principal modalidad de género informativo propio del periodismo: la noticia. Los objetivos de esta asignatura se centran en conocer detalladamente las fases y mecanismos del proceso de elaboración de la información periodística desde una óptica teóricopráctica (Benavides, 2004) adaptada al cambio digital (Edo, 2009), dominar en la práctica los métodos de trabajo que se aplican en la producción de productos periodísticos; así como los registros y las modalidades de expresión específicas del periodismo (Núñez Ladevèze , 1993); (Casals, 2004).

En segundo lugar, la asignatura Géneros Periodísticos II (PE0919- Carácter obligatorio. 6 créditos ECTS) es una materia impartida durante el segundo cuatrimestre del segundo curso que se centra en el estudio de los diferentes tipos de productos y formatos, basados en la información e interpretación, que usualmente se utilizan en el campo del periodismo. Para ello, se vale del concepto de "género periodístico" (Martin Vivaldi, 1987). En este sentido, junto a la explicación de esta noción, se repasan los principales géneros informativos e interpretativos (Abril Vargas, 2003) del periodismo actual: entrevista, reportaje, crónica, perfil, etc. Junto a su estudio teórico, esta asignatura insiste, especialmente, en su abordaje práctico para capacitar al alumnado en la elaboración de estos diferentes productos periodísticos (Salaverría, 2005).

Así, los objetivos de la asignatura serán conocer detalladamente lo concerniente al conocimiento teórico-práctico de los géneros interpretativos en prensa, dominar en la práctica los métodos de trabajo que se aplican en la redacción de textos interpretativos $\mathrm{y}$, al mismo tiempo, los registros y las modalidades de expresión específicas del periodismo interpretativo: reportaje, crónica, entrevista y perfil (Paniagua, 2009, p. 19-62).

En tercer lugar, la asignatura Géneros Periodísticos de Análisis y Opinión (PE0930Carácter obligatorio. 6 créditos ECTS) es una materia impartida durante el segundo 
Su objetivo es capacitar al alumnado en la realización de piezas periodísticas vinculadas a los diferentes géneros de opinión y análisis. En este sentido, se definen las características generales de los géneros periodísticos de opinión y su lleva a cabo una tipología de los mismos (Abril Vargas, 1999). Entre éstos, se dedica una especial atención a las columnas, los editoriales, las críticas, las tertulias y los debates, entre otros (León Gross, 1996).

Además, de ofrecer un acercamiento a los rasgos de cada uno de ellos, se potencia la realización y ejecución de este tipo de piezas entre el alumnado. Para ello, la asignatura se reviste de un fuerte componente práctico e incide en la presentación de los métodos de trabajo destinados a la elaboración de estas piezas de análisis y opinión (Santamaría y Casals, 2000); (de Diego, 2009).

Y por último, la asignatura Periodismo Especializado (PE0931- Carácter obligatorio. 6 créditos ECTS) es una materia impartida durante el primer cuatrimestre del segundo curso del grado en Periodismo que ofrece una introducción de carácter teóricopráctico en el ámbito del periodismo especializado, también conocido como Información periodística especializada, entendido como una profundización metodológica en la práctica profesional periodística. este sentido, se centra en el estudio de esta materia desde un punto de vista general tratando de aportar una base teórica sobre la especialización (Berganza, 2005; Esteve \& Moncholí, 2007) en el campo periodístico, presentando sus principales métodos de trabajo específicos y detallando las áreas de especialización profesional más relevantes.

Por este motivo, el desarrollo del temario comienza definiendo qué se entiende por especialización en el campo periodístico a nivel teórico y analizando su evolución histórica de estos estudios en las últimas décadas (Fernández del Moral, 2005). A continuación, se profundiza en la explicación detallada de sus métodos de trabajo específicos, que adoptan, fundamentalmente, las técnicas profesionales del periodismo de investigación (Quesada, 1998; 2004; Martínez, 2010). Y finalmente, se presentan las principales áreas de especialización, prestando una especial atención a dos ámbitos profesionales concretos: el Periodismo de Servicio (Diezhandino, 1994) y el Periodismo de Precisión (Meyer, 1993); (Dader, 1997); (Perez Herrero, 2004).

\section{Competencias profesionales asociadas al módulo}

Como se ha resaltado, el conjunto de estas asignaturas se entienden como medulares dentro del plan de estudios del grado de Periodismo en la Universitat Jaume I (UJI), ya que están directamente relacionadas con la adquisición deimportantes capacidades v competencias profesionales cercanas. Dada su afinidad, estas cuatro asignaturas 
e) Razonamiento crítico.

Por otra parte, las competencias específicas propias de cada asignatura muestran su singularidad y la progresividad en el estudio de los géneros periodísticos. A continuación se presentan las citas competencias de forma ordenada en el tiempo.

Competencias específicas que adquiere el estudiante con la asignatura Géneros Periodísticos:

a) Competencia para dominar los registros y las modalidades de expresión específicas del periodismo.

b) Capacidad para elaborar productos periodísticos de carácter informativo.

c) Competencia para conocer y dominar en la práctica los métodos de trabajo que se aplican en la producción de productos periodísticos.

d) Competencia para elaborar noticias periodísticas

e) Competencia para conocer detalladamente las fases y mecanismos del proceso de elaboración de la información periodística desde una óptica teórica.

f) Capacidad para conocer las principales problemáticas que, actualmente, afectan al periodismo.

Competencias específicas que adquiere el estudiante con la asignatura Géneros Periodísticos II:

a) Competencia para conocer detalladamente los diferentes tipos y formatos de productos periodísticos a partir de su división en diferentes géneros periodísticos basados en la información.

b) Capacidad para elaborar entrevistas periodísticas.

c) Competencia para elaborar crónicas periodísticas.

d) Competencia para elaborar reportajes periodísticos.

e) Capacidad para elaborar productos periodísticos complejos.

f) Comunicación oral y escrita en lengua nativa.

g) Capacidad para dominar las diferentes modalidades de expresión periodística propias de cada uno de los géneros informativos.

Competencias específicas que adquiere el estudiante con la asignatura Géneros Periodísticos de Análisis y Opinión:

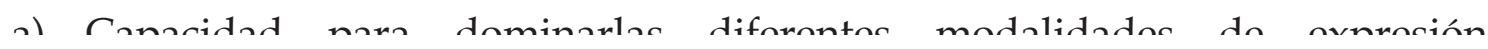


c) Capacidad para elaborar críticas periodísticas.

d) Competencia para elaborar artículos editoriales de naturaleza periodística.

e) Capacidad para llevar a cabo tertulias y debates de naturaleza periodística.

f) Competencia para elaborar productos periodísticos de análisis y opinión.

Competencias específicas que adquiere el estudiante con la asignatura Periodismo Especializado:

a) Capacidad para identificar y analizar los principales ámbitos y áreas del periodismo especializado: político y parlamentario, deportivo, cultural, local, institucional, económico, de sucesos y tribunales, científico y medioambiental.

b) Competencia para entender y contextualizar las implicaciones de la especialización periodística en el trabajo de los profesionales del periodismo.

c) Capacidad para conocer desde una perspectiva teórico-práctica las características, lógicas y problemáticas del periodismo de servicio, entendido como una especialización periodística.

d) Competencia para conocer desde una perspectiva teórico-práctica las características, lógicas y problemáticas del periodismo de precisión, entendido como una especialización periodística.

e) Competencia para conocer y aplicar los métodos de trabajo del periodismo especializado.

f) Competencia para elaborar productos informativos basados en los principios del periodismo especializado.

\section{Criterio de organización de las prácticas}

Como se ha justificado con anterioridad, más allá de su fundamentación teórica, estas cuatro asignaturas que conformarían el módulo de Redacción Periodística se caracterizan por una carga eminentemente práctica que busca capacitar a los alumnos/as en la elaboración profesional de estos contenidos periodísticos. En consecuencia, el peso de la parte práctica representa, respectivamente, el 60\% en Géneros Periodísticos, el 75\% en Géneros Periodísticos II, el 70\% en Géneros Periodísticos de Análisis y Opinión, y el 65\% en Periodismo Especializado; del total de la evaluación. De esta forma la base fundamental de la calificación de los alumnos/as recaerá en la evaluación de los diferentes ejercicios y seminarios propuestos por el profesor (Tembrik, 1988). 
Precisamente, la parte práctica de la asignatura Géneros Periodísticos contempla como pruebas de evaluación (entre paréntesis su valor porcentual en la nota final): Prototipos (35\%), Resolución de casos (10\%), Elaboración de trabajos académicos (5\%), Presentaciones orales y pósters (5\%), Observación/ejecución de tareas prácticas (5\%). Por su parte el sistema de evaluación de la asignatura Géneros Periodísticos II en su apartado práctico está compuesto por los siguientes ítems: Prototipos (40\%), Proyectos $(10 \%)$, Resolución de casos $(10 \%)$, Elaboración de trabajos académicos (5\%), Observación y ejecución de tareas y prácticas (5\%) y Presentaciones orales y pósters (5\%). En el caso de la materia Géneros Periodísticos de Análisis y Opinión la evaluación de la parte práctica queda conformada por: Elaboración de trabajos académicos (10\%), Observación de tareas y prácticas (10\%) y Prototipos (50\%). Por último, Periodismo Especializado resuelve la evaluación de la parte práctica con las diferentes pruebas: Elaboración de trabajos académicos (10\%), Observación de tareas y prácticas (10\%), Presentaciones orales y pósters (5\%) y Prototipos (40\%).

Uno de los hechos fundamentales a resaltar en el planteamiento metodológico de las prácticas es el desdoblamiento en dos grupos de 45 estudiantes en cada una de las asignaturas que aglutina el módulo de Redacción Periodística para desarrollar la sesiones de dos horas de prácticas semanales.

Por otra parte, decidimos que los ejercicios prácticos en las cuatro asignaturas se trabajarán y presentarán principalmente de forma individual con el objetivo que equiparar tales actividades al trabajo real que se puede realizar en la redacción de cualquier medio de comunicación. La asistencia a las clases prácticas de ambas asignaturas es obligatoria. Aquellos alumnos/as que no cumplan un porcentaje mínimo de asistencia del 85\% quedarán suspendidos en la primera convocatoria. Para hacer media y superar estas materias en su vertiente práctica, cada alumno/a deberá obtener, como mínimo, un aprobado en cada uno de los sistema de evaluación (Rosales, 1990).

Los alumnos que, por motivos justificados documentalmente (coincidencia del horario laboral con el horario de clases), no puedan asistir a las clases prácticas de alguna de estas asignaturas deberán ponerse en contacto con el profesorado durante las tres primeras semanas del curso para notificar y acreditar su situación. Una vez comprobada, el profesorado le confeccionará un itinerario de prácticas personalizado e individualizado para superar la asignatura. En tales casos, el alumno pierde la puntación correspondiente a “Observación/ejecución de tareas y prácticas” (10\%).

Al mismo tiempo, los alumnos/as tienen la obligación de asistir al seminario organizado para cada una de las cuatro asignaturas $\mathrm{v}$ aue aparece contemplado 
Dicho seminario presenta la conferencia de un profesional de reconocido prestigio en el ámbito del Periodismo a partir de la cual los alumnos/as deberán elaborar una pieza informativa-interpretativa determinada por el profesor. Como se ha resaltado, la asistencia al seminario de la asignatura es obligatorio. En caso contrario, el alumno/a buscará y pactará con el profesorado la asistencia a una conferencia relacionada con la temática de la asignatura, de la que deberá entregar un ejercicio de iguales características al resto de los alumnos/as.

\subsection{Necesaria coordinación entre las asignaturas del módulo}

Sin lugar a dudas, el estudio de los géneros periodísticos, tanto en su vertiente práctica como teórica (Gomis, 2008), constituye uno de los pilares básicos de la formación universitaria para los estudiantes del grado en Periodismo en la Universitat Jaume I de Castellón (UJI). Es seguro que, cualquiera que sea la actividad profesional que desarrollen como graduados en el campo del Periodismo necesitarán una consistente formación en el campo de la redacción, valoración y análisis del diferentes textos periodísticos.

La principal preocupación que subyace es que los futuros graduados sean capaces de conocer las diferentes estrategias y técnicas de redacción con el fin de aprovechar al máximo sus cualidades comunicativas. Como se ha significado con anterioridad, en relación a los objetivos propuestos podemos destacar como en estas asignaturas prevalece la adquisición de capacidades y competencias estrechamente ligadas con la vertiente práctica.

Comprendemos que la información, interpretación y opinión periodística debe entenderse, en un sentido amplio y para ello, debe armonizar tanto una sólida vertiente teórica como una acentuada visión práctica, que incida en la praxis de la profesión, ofreciendo un conocimiento detallado sobre las técnicas y rutinas productivas del Periodismo. Este último aspecto revela la existencia de toda una serie de métodos de trabajo específicos y distintivos de la profesión periodística, conectados al ámbito de conocimiento de las Ciencias de la Comunicación.

Sólo la correcta combinación entre teoría y praxis de carácter específico facilita un acercamiento al Periodismo, evitando caer en el error de considerarlo una mera suma de recetas destinadas a la confección de productos periodísticos, o un cajón de sastre en el que tengan cabida, de forma arbitraria, aproximaciones ajenas al conocimiento científico (Ortega y Gasset, 1966) concreto de este ámbito. Se trata, pues, de estar a la altura de las actuales tendencias de innovación educativa, preocupadas en especial por la armonización de los estudios en el entorno del Espacio Europeo de Educación 
Las clases prácticas, como ya se ha señalado, conforman una parte sustancial en la programación de las asignaturas inscritas en el módulo de Redacción Periodística. Asimismo, en las sesiones prácticas se tratará fundamentalmente de que los alumnos/as trasladen los conocimientos teóricos adquiridos a la realidad concreta de la praxis periodística. De este modo, las clases se basarán siempre en unos conocimientos teóricos previos con el objetivo de posibilitar la clarificación de conceptos periodísticos, la eliminación de fallos en el aprendizaje teórico y el desarrollo de habilidades concretas (Hernández, 1989).

En consecuencia, se entienden las prácticas como, a diferencia de las clases teóricas, un espacio donde los alumnos/as tienen un mayor protagonismo y donde se desarrolla una gran actividad. La mayor parte de las prácticas propuestas consisten en actividades de redacción periodística donde se persigue la máxima participación de los alumnos/as. En este caso, el profesor realiza una tarea de asesoramiento, supervisión y guía, además de estímulo continuo para lograr que el alumno/a elija, promueva su ingenio y creatividad en la búsqueda de soluciones para cada ejercicio que se plantea.

Por todo ello, y por la ubicación sucesiva de las asignaturas inscritas en el módulo de Redacción Periodística en los semestres y curso del Grado, y el fuerte carácter escalonado de sus contenidos y competencias profesionales asociadas; consideramos que demanda una coordinación pedagógica para su correcto desarrollo. Además de la importancia y carácter progresivo de las asignaturas que conformarían este módulo docente, la experiencia docente de estos primeros años de implantación del grado de Periodismo advierte la necesidad de realizar una propuesta docente concreta que coordine eficazmente los cuatro programas de prácticas del módulo de Redacción Periodística de acuerdo las principios metodológicos de la EEES.

Esta propuesta pretende evitar solapamientos entre los diferentes ejercicios, y así optimizar el tiempo dedicado a cada actividad con el propósito de realizar una distribución efectiva, tanto de los objetivos docentes propuestos como de los resultados de aprendizaje buscados. Tras revisar las respectivas guías docentes de las cuatro asignaturas seleccionadas, planteamos a continuación una propuesta metodológica que coordine efectivamente el programa de prácticas de las asignaturas circunscritas al módulo de Redacción Periodística.

\subsection{Propuesta de coordinación docente}

Así, esta redefinición de la parte práctica de estas asignaturas tan profundamente relacionadas presenta tres grandes aportaciones. En primer lugar, la definición 
Y por último, un cronograma global que articula su tratamiento coordinado de los ejercicios seleccionados para cada asignatura a lo largo de su curso correspondiente (desarrollo en paralelo de ambos grupos de desdoble de prácticas).

\section{Definición del programa de prácticas}

En la siguiente Tabla 2 se desglosa de forma progresiva el programa de las cuatro asignaturas que componen el módulo de Redacción Periodística.

Tabla 2. Definición programas prácticas de las asignaturas del módulo de Redacción

Periodística.

\begin{tabular}{|c|c|}
\hline Géneros Periodísticos & \\
\hline Título de la práctica & Descripción de la práctica \\
\hline $\begin{array}{l}\text { P.1. Localización y } \\
\text { análisis de fuentes } \\
\text { informativas }\end{array}$ & $\begin{array}{l}\text {-Buscar fuentes en dos textos de portada escogidos y } \\
\text { seleccionados por el alumno/a. } \\
\text {-Enumerar y clasificar las fuentes según su tipología. } \\
\text {-Resaltar las diferentes modalidades de citación de fuentes. }\end{array}$ \\
\hline $\begin{array}{l}\text { P.2. Localización y } \\
\text { análisis de elementos } \\
\text { del estilo y lenguaje } \\
\text { periodístico }\end{array}$ & $\begin{array}{l}\text {-Elegir dos textos básicos para la localización de los ítems } \\
\text { requeridos. } \\
\text {-Identificar tanto de los rasgos estilísticos como los propios del } \\
\text { lenguaje periodísticos en dos textos escogidos por el alumno/a. } \\
\text {-Realizar una reflexión crítica de cada uno de estos elementos } \\
\text { inherentes al periodismo. }\end{array}$ \\
\hline $\begin{array}{l}\text { P.3. Redacción de } \\
\text { titulares informativos }\end{array}$ & $\begin{array}{l}\text {-El profesor facilitará una batería de noticias (aprox. } 3 \text { noticias) } \\
\text { y leads a los que habrá que asignar } 3 \text { titulares por cada pieza. }\end{array}$ \\
\hline $\begin{array}{l}\text { P.4. Redacción de } \\
\text { primeros párrafos } \\
\text { informativos }\end{array}$ & $\begin{array}{l}\text {-El profesor facilitará una batería de datos con los que el } \\
\text { alumno/a deberá redactar el primer párrafo de la información. }\end{array}$ \\
\hline
\end{tabular}

\begin{tabular}{l|l}
\hline $\begin{array}{l}\text { P.5. Redacción de una } \\
\text { noticia completa (I) }\end{array}$ & $\begin{array}{l}\text {-El profesor suministrará los datos necesarios para construir } \\
\text { una noticia completa, con cada uno de sus elementos } \\
\text { fundamentales. }\end{array}$ \\
\hline $\begin{array}{l}\text { P.6. Redacción de una } \\
\text { noticia completa (II) }\end{array}$ & $\begin{array}{l}\text {-El alumno/a seleccionará datos de actualidad referentes a la } \\
\text { UJI, además de una fotografía informativa apropiada para el } \\
\text { tema abordado. } \\
\text { a) El alumno/a realizará una propuesta con todos los datos } \\
\text { necesarios para su posterior redacción. } \\
\text { b) El profesor dará el visto bueno para la redacción de la } \\
\text { misma. A partir de ese momento el alumno/a comenzará su }\end{array}$
\end{tabular}




\begin{tabular}{|l|l|}
\hline $\begin{array}{l}\text { P.7. Redacción de una } \\
\text { noticia completa (III) }\end{array}$ & $\begin{array}{l}\text {-El alumno/a seleccionará un suceso o acontecimiento de } \\
\text { actualidad ajeno a la UJI, además de una fotografía informativa } \\
\text { apropiada para el tema abordado. } \\
\text { a) El alumno/a realizará una propuesta con todos los datos } \\
\text { necesarios para su posterior redacción. } \\
\text { b) El profesor dará el visto bueno para la redacción de la } \\
\text { misma. A partir de ese momento el alumno/a comenzará su } \\
\text { redacción }\end{array}$ \\
\hline
\end{tabular}

\begin{tabular}{|c|c|}
\hline \multicolumn{2}{|l|}{ Géneros Periodísticos II } \\
\hline Título de la práctica & Descripción de la práctica \\
\hline $\begin{array}{l}\text { P.1. Análisis } \\
\text { comparativo de los } \\
\text { elementos } \\
\text { interpretativos en } \\
\text { diferentes textos } \\
\text { periodísticos }\end{array}$ & $\begin{array}{l}\text {-El alumno/a seleccionará una misma noticia (propuesta por el } \\
\text { profesor) en tres diarios diferentes y analizará } \\
\text { comparativamente los elementos interpretativos en las } \\
\text { diferentes secciones (titulares, primer párrafo, cuerpo, } \\
\text { imágenes, etc.). }\end{array}$ \\
\hline $\begin{array}{l}\text { P.2. Redacción de un } \\
\text { reportaje }\end{array}$ & $\begin{array}{l}\text {-El alumno/a seleccionará datos de actualidad, además de una } \\
\text { fotografía informativa apropiada para el tema abordado. } \\
\text { a) El alumno/a realizará una propuesta con todos los datos } \\
\text { necesarios para su posterior redacción. } \\
\text { b) El profesor dará el visto bueno para la redacción del } \\
\text { reportaje. A partir de ese momento el alumno/a comenzará su } \\
\text { redacción. }\end{array}$ \\
\hline $\begin{array}{l}\text { P.3. Redacción de una } \\
\text { entrevista informativa } \\
\text { o de actualidad }\end{array}$ & $\begin{array}{l}\text {-El alumno/a seleccionará un personaje de actualidad, además } \\
\text { de realizar y aportar una fotografía informativa apropiada para } \\
\text { el tema abordado. La estructura utilizada para la entrevista } \\
\text { informativa será el modelo pregunta-respuesta. } \\
\text { a) El alumno/a realizará una propuesta con todos los datos } \\
\text { necesarios para su posterior redacción. } \\
\text { b) El profesor dará el visto bueno para la redacción de la } \\
\text { misma. A partir de ese momento el alumno/a comenzará su } \\
\text { redacción. }\end{array}$ \\
\hline
\end{tabular}

\begin{tabular}{|l|l|}
\hline $\begin{array}{l}\text { P.4. Redacción de una } \\
\text { entrevista } \\
\text { interpretativa }\end{array}$ & $\begin{array}{l}\text {-El alumno/a seleccionará un personaje de actualidad, además } \\
\text { de realizar y aportar una fotografía informativa apropiada para } \\
\text { el tema abordado. Se utilizará el estilo y el lenguaje propio de } \\
\text { este tipo de entrevista. } \\
\text { a) El alumno/a realizará una propuesta con todos los datos } \\
\text { necesarios para su posterior redacción. } \\
\text { b) El profesor dará el visto bueno para la redacción de la }\end{array}$ \\
\hline
\end{tabular}




\begin{tabular}{|l|l|}
\hline & $\begin{array}{l}\text { misma. A partir de ese momento el alumno/a comenzará su } \\
\text { redacción. }\end{array}$ \\
\hline $\begin{array}{l}\text { P.5. Redacción de una } \\
\text { crónica }\end{array}$ & $\begin{array}{l}\text { El alumno/a seleccionará un acontecimiento de actualidad, } \\
\text { además de realizar y aportar una fotografía informativa } \\
\text { apropiada para el tema abordado. } \\
\text { a) El alumno/a realizará una propuesta con todos los datos } \\
\text { necesarios para su posterior redacción. } \\
\text { b) El profesor dará el visto bueno para la redacción de la } \\
\text { misma. A partir de ese momento el alumno/a comenzará su } \\
\text { redacción. }\end{array}$ \\
\hline $\begin{array}{l}\text { P.6. Redacción de un } \\
\text { perfil de un personaje } \\
\text { de actualidad }\end{array}$ & $\begin{array}{l}\text { El alumno/a seleccionará un personaje, además de realizar y } \\
\text { aportar una fotografía informativa apropiada para el tema } \\
\text { abordado. } \\
\text { a) El alumno/a realizará una propuesta con todos los datos } \\
\text { necesarios para su posterior redacción. } \\
\text { b) El profesor dará el visto bueno para la redacción de la } \\
\text { misma. A partir de ese momento el alumno/a comenzará su } \\
\text { redacción. }\end{array}$ \\
\hline
\end{tabular}

\begin{tabular}{|l|l|}
\hline \multicolumn{2}{|l|}{ Géneros periodísticos de análisis y opinión } \\
\hline Título de la práctica & Descripción de la práctica \\
\hline $\begin{array}{l}\text { P.1. Análisis de piezas } \\
\text { periodísticas de } \\
\text { opinión }\end{array}$ & $\begin{array}{l}\text {-El alumno/a seleccionará una misma pieza de opinión } \\
\text { (propuesta por el profesor) en tres diarios diferentes y } \\
\text { analizará comparativamente los elementos opinativos en las } \\
\text { diferentes muestras seleccionadas (titulares, primer párrafo, } \\
\text { cuerpo, imágenes, etc.). }\end{array}$ \\
\hline $\begin{array}{l}\text { P.2. Elaboración de un } \\
\text { editorial periodístico }\end{array}$ & $\begin{array}{l}\text {-El alumno/a seleccionará un acontecimiento de actualidad, } \\
\text { además de realizar una prospección de otras editoriales sobre } \\
\text { el mismo tema. } \\
\text { a) El alumno/a realizará una primera propuesta al profesor } \\
\text { con todos los elementos necesarios para su posterior } \\
\text { redacción: estructura, enfoque, hilo argumental, título, etc. } \\
\text { b) El profesor dará el visto bueno para la redacción del misma. } \\
\text { A partir de ese momento el alumno/a comenzará la redacción } \\
\text { del editorial. }\end{array}$ \\
\hline
\end{tabular}

P.3. Elaboración de columnas periodisticas de opinión
-El alumno/a seleccionaxá un tema, además de realizax una prospección de otras columuas similares sobre el mismo tema. a) El alumno/a realizará una primera propuesta al profesor con todos los elementos necesarios para su posterior 


\begin{tabular}{|l|l|}
\hline & $\begin{array}{l}\text { redacción: estructura, enfoque, hilo argumental, título, etc. } \\
\text { b) El profesor dará el visto bueno para la redacción del misma. } \\
\text { A partir de ese momento el alumno/a comenzará la redacción } \\
\text { de la columna de opinión. }\end{array}$ \\
\hline $\begin{array}{l}\text { P.4. Elaboración de } \\
\text { críticas periodísticas de } \\
\text { opinión: La columna de } \\
\text { opinión }\end{array}$ & $\begin{array}{l}\text {-El alumno/a seleccionará un acontecimiento de actualidad, } \\
\text { además de realizar una prospección de otras críticas similares } \\
\text { sobre el mismo tema. } \\
\text { a) El alumno/a realizará una primera propuesta al profesor } \\
\text { con todos los elementos necesarios para su posterior } \\
\text { redacción: estructura, enfoque, hilo argumental, título, etc. } \\
\text { b) El profesor dará el visto bueno para la redacción del misma. } \\
\text { A partir de ese momento el alumno/a comenzará la redacción } \\
\text { de la crítica. }\end{array}$ \\
\hline $\begin{array}{l}\text { Elaboración de } \\
\text { artículos periodísticos } \\
\text { de opinión } \\
\text { profundidad }\end{array}$ & $\begin{array}{l}\text {-El alumno/a seleccionará un acontecimiento de actualidad, } \\
\text { además de realizar una prospección de otros artículos } \\
\text { similares sobre el mismo tema. } \\
\text { a) El alumno/a realizará una primera propuesta al profesor } \\
\text { con todos los elementos necesarios para sur posterior } \\
\text { redacción: estructura, enfoque, hilo argumental, título, etc. } \\
\text { b) El profesor dará el visto bueno para la redacción del misma. } \\
\text { A partir de ese momento el alumno/a comenzará la redacción } \\
\text { del artículo. }\end{array}$ \\
\hline
\end{tabular}

\begin{tabular}{|c|c|}
\hline \multicolumn{2}{|l|}{ Periodismo especializado } \\
\hline \multicolumn{2}{|l|}{ Prácticas individuales } \\
\hline Título de la práctica & Descripción de la práctica \\
\hline $\begin{array}{l}\text { P.1. Localización de } \\
\text { piezas de periodismo } \\
\text { especializado }\end{array}$ & $\begin{array}{l}\text {-El alumno/a elaborará una carpeta de trabajo a lo largo del } \\
\text { semestre a partir de la selección semanal de piezas de las } \\
\text { diferentes áreas de periodismo especializado tratadas en la } \\
\text { parte teórica de la asignatura (aproximadamente } 12 \text { piezas). }\end{array}$ \\
\hline $\begin{array}{l}\text { P.2. Puesta en común } \\
\text { de la carpeta de trabajo } \\
\text { elaborada durante los } \\
\text { primeros meses del } \\
\text { curso }\end{array}$ & $\begin{array}{l}\text {-A mitad de semestre, y por grupos de } 6-8 \text { personas, cada } \\
\text { alumno/a deberá realizar una explicación individual y } \\
\text { razonada de la selección de piezas de periodismo especializado } \\
\text { que componen la carpeta de trabajo propuesta en la Práctica } 1 \\
\text { hasta el momento. Cada alumno/a contará con tiempo } \\
\text { limitado (aprox. } 5-8 \text { minutos) para explicar sus criterios de } \\
\text { selección de cada una de sus piezas. } \\
\text { - Posteriormente el resto del grupo ha de pronunciarse sobre la } \\
\text { pertinencia de los criterios empleados. }\end{array}$ \\
\hline
\end{tabular}




\begin{tabular}{|c|c|}
\hline $\begin{array}{l}\text { Análisis y valoración } \\
\text { crítica de piezas de } \\
\text { periodismo } \\
\text { especializado }\end{array}$ & $\begin{array}{l}\text { (extensión mínima de } 2000 \text { palabras) en donde se analice el } \\
\text { conjunto de piezas de periodismo especializado seleccionadas } \\
\text { durante el semestre y se valore críticamente su adecuación } \\
\text { respecto a las características teóricas presentadas sobre este } \\
\text { tipo de periodismo. }\end{array}$ \\
\hline \multicolumn{2}{|l|}{ Prácticas en Grupo } \\
\hline Título de la práctica & Descripción de la práctica \\
\hline $\begin{array}{l}\text { P.4. Elaboración de } \\
\text { una pieza de } \\
\text { periodismo de servicio } \\
\text { ( } 500 \text { palabras) }\end{array}$ & $\begin{array}{l}\text {-A partir de la explicación de sus características teóricas y } \\
\text { metodológicas por parte del profesor, cada grupo deberá } \\
\text { preparar una pieza de periodismo de servicio a lo largo de dos } \\
\text { sesiones: en la primera, se deberá seleccionar el tema concreto } \\
\text { de la pieza, planificar el trabajo, y documentarse en } \\
\text { profundidad; y la segunda sesión se reserva para la redacción } \\
\text { y entrega definitiva del texto. }\end{array}$ \\
\hline 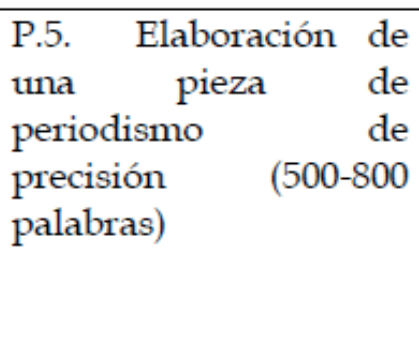 & $\begin{array}{l}\text {-A partir de la explicación de sus características teóricas y } \\
\text { metodológicas por parte del profesor, cada grupo deberá } \\
\text { preparar una pieza de peri periodismo de precisión a lo largo } \\
\text { de dos sesiones: en la primera, se deberá seleccionar el tema } \\
\text { concreto de la pieza, planificar el trabajo, y documentarse en } \\
\text { profundidad; y la segunda sesión se reserva para la redacción } \\
\text { y entrega definitiva del texto. }\end{array}$ \\
\hline $\begin{array}{l}\text { P.6. Puesta en común } \\
\text { resultados corrección } \\
\text { piezas de periodismo } \\
\text { especializado }\end{array}$ & $\begin{array}{l}\text {-A largo de una sesión completa, cada grupo de trabajo deberá } \\
\text { realizar una breve puesta en común ( } 10 \text { minutos) en donde se } \\
\text { haga una corrección argumentada y en profundidad de los dos } \\
\text { textos elaborados hasta el momento, ofreciendo un balance } \\
\text { completo del conjunto de dificultades encontradas, puntos de } \\
\text { interés y principales errores cometidos. }\end{array}$ \\
\hline $\begin{array}{lr}\text { P.7. Elaboración de un } \\
\text { reportaje } \\
\text { profundidad aplicando } \\
\text { la metodología } \\
\text { específica } \\
\text { periodismo } \\
\begin{array}{l}\text { especializado } \\
\text { palabras) }\end{array}\end{array}$ & $\begin{array}{l}\text {-En esta práctica final cada grupo de trabajo deberá elaborar } \\
\text { un reportaje en profundidad que se ajuste a los parámetros } \\
\text { teóricos y metodológicos del periodismo especializado } \\
\text { desarrollados a lo largo del curso. } \\
\text { a) El grupo podrá seleccionará libremente un área } \\
\text { especializada y realizará una propuesta con todos los datos } \\
\text { necesarios para su posterior redacción. } \\
\text { b) El profesor dará el visto bueno para la redacción de la } \\
\text { misma. A partir de ese momento cada grupo comenzará la } \\
\text { redacción de un texto final en donde se plasme el proceso de } \\
\text { aprendizaje llevado a cabo por cada grupo de alumnos } \\
\text { respecto a las claves teóricas y metodológicas del periodismo } \\
\text { onnonislizads }\end{array}$ \\
\hline
\end{tabular}




\subsection{Modelo de evaluación conjunto}

En segundo lugar, a partir del programa y los criterios generales de organización de las prácticas ya comentados, se presenta un modelo de evaluación basado en una serie de pruebas adaptadas a los objetivos de cada asignatura.

En primer lugar, tras la presentación de los objetivos y el programa de la asignatura, la metodología de trabajo, las fuentes bibliográficas y sistema de evaluación, se realizará una prueba inicial o test de prerrequisitos con la que se quiere medir el nivel de conocimientos previos que posee el estudiante. El test de prerrequisitos permite adecuar las intenciones docentes a los conocimientos previos y necesidades de los alumnos. Decidir qué tipo de ayuda es la más adecuada cuando se accede a un nuevo aprendizaje, requiere conocer cómo se ha resuelto la fase anterior, cuáles son los esquemas de conocimiento del alumno, su actitud, interés, nivel de competencia curricular, etc. Precisamente, en la docencia que nos ocupa resulta fundamental la aplicación de este proceso de evaluación debido a la heterogeneidad de conocimientos con los que los alumnos acceden a matricularse en la misma.

Posteriormente, y aunque se trata de un módulo de asignaturas con un temario amplio y heterogéneo, donde los contenidos están interrelacionados: teoría y práctica; y siguiendo el modelo de evaluación continua, no se impone la necesidad de realizar una prueba a mitad del semestre o ensayo de evaluación. Debido a la condición semestral de las asignaturas y a la valoración continua que el profesor realizará de las prácticas realizadas por los alumnos, donde el estudiante ya toma conciencia de cómo va su proceso de aprendizaje y constituye, a su vez, un barómetro fiable de cómo va el desarrollo del programa dispuesto.

Sin embargo, en el caso de precisar el profesor una información más precisa acerca de la evolución de un alumno determinado, se contempla la asistencia del mismo a las tutorías estipuladas para que tanto el docente como el estudiante adquieran conciencia del grado real de comprensión de la materia y corregir las posibles desviaciones del proceso instructivo de forma individual.

Finalmente, al término del semestre tendrá lugar una prueba final para realizar la evaluación de los contenidos más teóricos de las asignaturas. Así, la evaluación final permite conocer si el grado de aprendizaje se ha conseguido o no, y cuál es el punto de partida para una nueva intervención. La prueba final toma datos de la evaluación formativa, es decir, los obtenidos durante el proceso, y añade a éstos, otros obtenidos de forma más puntual. 
Dichas pruebas serán de respuesta limitada, es decir, con preguntas concretas que demandan respuestas breves, y preguntas de selección (verdadero-falso y elección múltiple). De forma paralela, se hará una evaluación de toda una serie de trabajos prácticos, ya presentados, que los alumnos realizarán tanto de forma individual como en grupo. Siempre se valorará la calidad y originalidad del trabajo en base a unos criterios que el alumno conocerá a priori, gracias a la documentación de las fichas de prácticas facilitada por el profesor.

\subsection{Cronograma de prácticas}

En la siguiente Tabla 3 se resumen el cronograma anual de prácticas de las cuatro asignaturas que componen el módulo de Redacción Periodística.

Tabla 3. Cronograma anual de prácticas de las asignaturas del módulo de Redacción Periodística

\begin{tabular}{|c|c|l|}
\hline \multicolumn{2}{|l|}{ Géneros Periodísticos } \\
\hline Semana & Práctica & Descripción actividad \\
\hline 1 & 0 & Presentación del programa de prácticas de la asignatura \\
\hline 2 & 1 & P.1. Inicio y trabajo en el aula \\
\hline 3 & $1+2$ & $\begin{array}{l}\text { P.1. Exposición de los resultados en el aula y entrega }+ \\
\text { P.2. Inicio }\end{array}$ \\
\hline 4 & 2 & Trabajo en el aula \\
\hline 5 & $2+3$ & P.2. Exposición de los resultados en el aula + P.3. inicio \\
\hline 6 & 3 & Trabajo en el aula \\
\hline 7 & $3+4$ & P. 4. Inicio y trabajo en el aula + P.3. entrega \\
\hline 8 & $4+5$ & P. 4. Entrega + P.5 inicio \\
\hline 9 & 5 & Trabajo en el aula \\
\hline 10 & $5+6$ & P.5. Entrega + P.6. inicio y trabajo en el aula \\
\hline 11 & 6 & P.6. Trabajo en el aula \\
\hline 12 & $6+7$ & P.6. Entrega + P.7. Inicio y trabajo en el aula \\
\hline 13 & 7 & P.7. Trabajo en el aula \\
\hline 14 & 7 & P.7 Entrega y conclusiones \\
\hline
\end{tabular}




\begin{tabular}{|c|c|l|}
\hline \multicolumn{2}{|l|}{ Géneros Periodísticos II } \\
\hline Semana & Práctica & Descripción actividad \\
\hline 1 & 0 & Presentación del programa de prácticas de la asignatura \\
\hline 2 & 1 & P.1. Inicio y trabajo en el aula \\
\hline 3 & $1+2$ & $\begin{array}{l}\text { P.1. Exposición de los resultados en el aula y entrega }+ \\
\text { P.2. }\end{array}$ \\
\hline 4 & 2 & P.2. Trabajo en el aula \\
\hline 5 & $2+3$ & P.2. Entrega + P.3. inicio \\
\hline 6 & 3 & P.3. Trabajo en el aula \\
\hline 7 & $3+4$ & P.3. Entrega + P.4. inicio \\
\hline 8 & 4 & P.4. Trabajo en el aula \\
\hline 9 & $4+5$ & P.4. Entrega + P.5. inicio \\
\hline 10 & 5 & P.5. Trabajo en el aula \\
\hline 11 & $5+6$ & P.5. Entrega + P.6. inicio \\
\hline 12 & 6 & P.6. Trabajo en el aula \\
\hline 13 & 6 & P.6. Trabajo en el aula \\
\hline 14 & 6 & P.6. Entrega y conclusiones \\
\hline
\end{tabular}

Géneros Periodísticos de análisis y opinión

\begin{tabular}{|c|c|l|}
\hline Semana & Práctica & Descripción actividad \\
\hline 1 & 0 & Presentación del programa de prácticas de la asignatura \\
\hline 2 & 1 & P.1. Inicio + Trabajo en el aula \\
\hline 3 & 1 & P.1. Exposición de los resultados en el aula + Entrega \\
\hline 4 & 2 & P.2. Inicio + Trabajo en el aula \\
\hline 5 & 2 & P.2. Trabajo en el aula \\
\hline 6 & 2 & P.2. Entrega + Valoraciones \\
\hline 7 & 3 & P.3. Inicio + Trabajo en el aula \\
\hline 8 & 3 & P.3. Entrega + valoraciones \\
\hline 9 & 4 & P.4. Inicio Trabajo en el aula \\
\hline
\end{tabular}

\begin{tabular}{|l|l|l|}
\hline 10 & 4 & P.4. Trabajo en el aula \\
\hline 11 & 4 & P.4. Entrega + valoraciones \\
\hline 12 & 5 & P.5. Inicio + Trabajo en el aula \\
\hline 13 & 5 & P.5. Trabajo en el aula \\
\hline 14 & 5 & P.5. Entrega y conclusiones finales \\
\hline
\end{tabular}




\begin{tabular}{|c|c|l|}
\hline \multicolumn{3}{|c|}{ Periodismo especializado } \\
\hline Semana & Práctica & Descripción actividad \\
\hline 1 & 0 & Presentación del programa de prácticas de la asignatura \\
\hline 2 & 1 & P.1 Inicio y trabajo en el aula \\
\hline 3 & 4 & P.4 Inicio y trabajo en el aula \\
\hline 4 & 4 & P.4 Trabajo en el aula \\
\hline 5 & $4+2$ & P.4 Entrega + P.2 Puesta en común en el aula \\
\hline 6 & 5 & P.5 Inicio y trabajo en el aula \\
\hline 7 & 5 & P.5 Trabajo en el aula \\
\hline 8 & 5 & P.5 Trabajo en el aula \\
\hline 9 & $5+6$ & P.5 Trabajo en el aula y entrega \\
\hline 10 & 6 & P.6. Puesta en común en el aula \\
\hline 11 & 7 & P.7. Inicio y trabajo en el aula \\
\hline 12 & 7 & P.7 Trabajo en el aula \\
\hline 13 & $3+7$ & P.3. Entrega informe final + P.7 trabajo en el aula \\
\hline 14 & 7 & Entrega P.7 y conclusiones \\
\hline
\end{tabular}

\section{CONCLUSIONES}

Tal como se han presentado y contextualizado, el conjunto de asignaturas vinculadas a la redacción periodística representan un contenido central dentro del plan de estudios del Grado en Periodismo en la Universitat Jaume I (UJI). Su decidida orientación práctica y su conexión directa con la adquisición de importantes competencias profesionales en la prensa tradicional y en las nuevas formatos digitales en Internet hace del módulo de Redacción Periodística uno de los ejes fundamentales de los estudios de periodismo en su adaptación al Espacio Europeo de Educación Superior (EEES).

Ante el reto de organizar el desarrollo de este módulo docente en el segundo y tercer curso del Grado, se hace imprescindible un criterio docente claro y una notable coordinación pedagógica para evitar solapamientos, optimizar el tiempo y ofrecer una distribución efectiva para el cumplimiento de los objetivos y la obtención de los resultados de aprendizaje buscados (competencias profesionales).

Así, en este momento de implantación progresiva del grado de Periodismo en las diferentes universidades española, el reto consiste en hacer efectiva en los próximos años un verdadero desarrollo de los planes de estudio de acuerdo a los principios del EEES. En este sentido, confiamos que la propuesta de coordinación docente 


\section{REFERENCIAS}

Abril Vargas, N. (1999). Periodismo de opinión. Madrid: Síntesis.

Armentia, J.I. (2009). Redacción informativa en prensa. Barcelona: Ariel.

Armentia, J.I.; Caminos, J.M. (2003): Fundamentos de periodismo impreso. Barcelona: Ariel.

Benavides, J.L. (2004). Escribir en prensa. Madrid: Pearson.

Berganza, M.R. (2005). Periodismo especializado. Madrid: Ediciones Internacionales Universitarias.

Boyer, E. L. (1990). Scholarship Reconsidered: Priorities of the Professorate. New Jersey: The Princeton University Press

Casals, M. J. (2004). Mensaje periodístico y sociedad del conocimiento. Madrid: Fragua.

Casasús, J.M. (1988). Iniciación a la Periodística. Barcelona: Teide.

Cruz Tomé, M. A. de la (1993). Formación pedagógica de los profesores universitarios de la Universidad Autónoma de Madrid: balance de dos años de existencia del Servicio de Ayuda a la Docencia Universitaria. En Formación pedagógica del profesorado universitario y calidad de la educación. Valencia: Servei de Formació Permanent.

Dader, J.L. (1997). Periodismo de precisión. Vía socioinformática de descubrir noticias. Madrid: Síntesis.

De Diego, A. (2009). La crónica periodística:un género personal. Madrid: Universitas.

Diezhandino, M.P. (1994). Periodismo de servicio. La utilidad como complemento informativo en Time, Newsweek y U.S. News and World Report, y unos apuntes del caso español. Barcelona: Bosch.

Edo, C. (2009). Periodismo informativo e interpretativo: el impacto de Internet en la noticia, las fuentes y los géneros. Sevilla: Comunicación Social.

Esteve Ramírez, F.; Moncholi M. A (2007). Teoría y técnicas del periodismo especializado. Madrid: Fragua. 
Gomis, L. (2008). Teoría de los géneros periodísticos. Barcelona: UOC.

Hernández, P. (1989). Diseñar y enseñar. Teoría y técnicas de la programación y del Proyecto Docente. Tenerife: Instituto de Ciencias de la Educación de la Universidad de la Laguna.

Ibañez-Martín, J. A. (1990). Dimensiones de la competencia profesional del profesor de Universidad. Revista española de pedagogía, 186.

León Gross, T. (1996): El artículo de opinión. Barcelona: Ariel Comunicación.

López De Zuazo, A. (1977). Diccionario de Periodismo. Madrid: Pirámide.

Martín Vivaldi, G. (1987). Géneros periodísticos. Madrid: Paraninfo.

Martínez Albertos, J.L. (2004). Curso general de redacción periodística. Madrid: Thomson.

Martínez, L. (2010). Periodismo especializado: teoría y práctica de la especialización informativa. Murcia: Diego Marín.

Meyer, P. (1993). Periodismo de precisión. Nuevas fronteras para la investigación periodística. Barcelona: Bosch.

Michavila, F.; Calvo, B. (1998). La Universidad Española hoy. Propuesta para una política universitaria. Madrid: Síntesis.

Núñez Ladevèze, L. (1993) Métodos de redacción periodística y fundamentos del estilo. Madrid: Síntesis.

Ortega y Gasset, J. (1966). Misión de la Universidad. Obras Completas (Tomo IV). Madrid: Editorial Revista de Occidente.

Paniagua, P. (2009). Información e interpretación en periodismo. Hacia una nueva teoría de los géneros periodísticos. Barcelona: UOC.

Pérez Herrero, P. (2004). El periodismo de precisión como técnica para la información especializada. En Periodismo especializado. Barcelona: Ariel. 
Rosales, C. (1990). Evaluar es reflexionar sobre educación. Madrid: Narcea.

Salaverría, R. (2005). Redacción periodística en Internet. Pamplona: EUNSA.

Santamaría, L. \& Casals, M.J. (2000). La opinión periodística. Argumentos y géneros para la persuasión. Madrid: Fragua.

Stufflebeam, D. L. \& Shinkfield, A. J. (1987). Guía práctica para profesores. Guía teórica y práctica. Barcelona: Paidós.

Tenbrink, T.D. (1998). Evaluación. Guía práctica para profesores. Madrid: Narcea.

Hugo Doménech Fabregat: profesor colaborador del Departamento de Ciencias de la Comunicación de la Universitat Jaume I. En la actualidad imparte clases tanto en el Grado en Periodismo como en el de Publicidad y RRPP de la misma Universidad.

Pablo López Rabadán: profesor ayudante del Departamento de Ciencias de la Comunicación de la Universitat Jaume I. En la actualidad imparte clases en el Grado en Periodismo de la misma Universidad. 